\title{
Cx43 phosphorylation on S279/282 and intercellular communication are regulated by $\mathrm{IP}_{3} / \mathrm{IP}_{3}$ receptor signaling
}

Man Kang ${ }^{1 \dagger}, \mathrm{Na} \mathrm{Lin}^{2 \dagger}$, Chen Li ${ }^{1,4}$, Qingli Meng ${ }^{1}$, Yuanyuan Zheng ${ }^{1}$, Xinxin Yan ${ }^{1}$, Jianxin Deng ${ }^{2}$, Yang Ou ${ }^{2}$, Chao Zhang ${ }^{1}$, Junqi $\mathrm{He}^{3}$ and Dali Luo ${ }^{1 *}$

\begin{abstract}
Background: Inositol 1,4,5-trisphosphate receptor $\left(\mathrm{IP}_{3} \mathrm{R}\right)$ plays a pivotal role in the $\mathrm{Ca}^{2+}$ release process in a variety of cell types. Additionally, $I \mathrm{P}_{3} \mathrm{R}$ is distributed in ventricular intercalated discs, but its function(s) in this particular site remains unknown. Connexin (CX43), the predominant gap junction (GJ) protein in ventricular myocardium, is linked to several signaling pathways that regulate $\mathrm{Cx43}$ properties by (de)phosphorylation on multiple residues. Here, we investigated the regulatory role of $\mathrm{IP}_{3} \mathrm{R}$ in cell-cell communication and the mechanism(s) underlying this effect.
\end{abstract}

Results: In neonatal rat and adult mouse ventricular myocytes $\mathbb{P}_{3} R$ co-localized and co-immunoprecipitated with Cx43 in GJ plaques detected by immunostaining and western blot assays. Blocking $\mathrm{IP}_{3} R$ with antagonists or silencing pan-IP $P_{3}$ expression with shRNA hindered the 6-carboxyfluorescein (6-CFDA) diffusion through GJs and desynchronized $\mathrm{Ca}^{2+}$ transients among confluent neonatal myocytes in culture, whereas stimulation of $I P_{3} R$ with $I_{3}$ ester or ATP exerted the opposite effect. Likewise, 6-CFDA propagation through GJs was modulated by $\mathrm{I}_{3} \mathrm{R}$ activation or inhibition in cell pairs of isolated adult cardiomyocytes. Furthermore, $I P_{3} R$ activation or $I P_{3} R$ suppression promoted or suppressed, respectively, Cx43 phosphorylation on S279/282. Site-directed mutagenesis indicated that expression of a mutant Cx43-S282A (alanine) inhibited S279/282 phosphorylation and GJ permeability, while the S279A mutant showed the opposite effect in ventricular myocytes. Expression of these mutants in HEK293 cells revealed that cells with a dual S279/282 mutation failed to express exogenous Cx43, whereas cells with a single S279 or S282 mutation displayed Cx43 overexpression with increased phosphorylation of S279/282 and promotion of intercellular communication.

Conclusions: These results demonstrated, for the first time, that $\mathrm{IP}_{3} \mathrm{R}$ physically interacts with $\mathrm{C} \times 43$ and participates in the regulation of Cx43 phosphorylation on S279/282, thereby affecting GJ intercellular communication in ventricular myocytes.

Keywords: Inositol 1,4,5-trisphosphate receptor, Gap junction, Connexin 43, Serine 279/282 phosphorylation, Intercellular communication, Ventricular myocyte

\section{Background}

In heart, gap junctions (GJs) serve as intercellular communication channels to confer direct ion exchange and synchronization of electrical excitation between adjacent myocytes, thus allowing rhythmic coordinated myocardium contraction. In addition, they permit intercellular exchange of metabolites and small signaling

\footnotetext{
* Correspondence: luodl@ccmu.edu.cn

${ }^{\dagger}$ Equal contributors

'Department of Pharmacology, Capital Medical University, Beijing 100069, China

Full list of author information is available at the end of the article
}

molecules including cAMP, inositol 1,4,5-trisphosphate $\left(\mathrm{IP}_{3}\right)$, and ATP, to maintain cellular homeostasis and couple biological activities between cells in the myocardium $[1,2]$. Abnormalities in GJs promote cardiac arrhythmias and apoptosis, two major complicating features of multiple cardiac pathologies [2-5]. Furthermore, mutations in the connexin gene, the main protein constituent of GJs, are linked to various human diseases, including cardiovascular anomalies [6-8]. Physiologically, connexin 43 (Cx43), the predominant GJ protein in ventricular myocardium, is phosphorylated on multiple residues, a

\section{Biomed Central}

(c) 2014 Kang et al.; licensee BioMed Central Ltd. This is an Open Access article distributed under the terms of the Creative Commons Attribution License (http://creativecommons.org/licenses/by/2.0), which permits unrestricted use, distribution, and reproduction in any medium, provided the original work is properly credited. The Creative Commons Public Domain Dedication waiver (http://creativecommons.org/publicdomain/zero/1.0/) applies to the data made available in this article unless otherwise stated. 
process that regulates its properties including assembling, trafficking, degradation, and electrical and metabolic coupling [1,2,9-12]. A variety of kinases, including protein kinase $\mathrm{C}$ (PKC), mitogen-activated protein kinase (MAPK), and Src, and connexin partners, such as ZO-1 and tublin, can alter $\mathrm{Cx} 43$ phosphorylation as well as its properties, and thereby affect heart function [10-14]. Of interest is phosphorylation of S262, S368, S279, and S282, which has been identified to link with the PKC, MAPK and PKA pathways, however, the precise role of a single kinase or $\mathrm{Cx} 43$ protein partner in the regulation of $\mathrm{Cx} 43$ phosphorylation is far from clear, because a kinase can phosphorylate more than one site and one site can be phosphorylated by various kinases and signaling pathways at the same time [12-15]. Thus, combined approaches including the use of $\mathrm{Cx} 43$ phosphorylation site-specific antibodies and alanine or aspartic acid (or glutamic acid) substitution as a silencer or a mimetic for phosphorylation can overcome these problems.

$\mathrm{IP}_{3}$ receptor $\left(\mathrm{IP}_{3} \mathrm{R}\right)$ protein, a family of three highly conserved isoforms, is expressed ubiquitously in the endoplasmic reticulum (ER) and plays a pivotal role in controlling the intracellular $\mathrm{Ca}^{2+}$ mobilization in non-electrical excitable cells. Though the three isoforms are found in the mammalian atrium and ventricles, they do not appear to be essential for cardiac excitation-contraction coupling [16-19]. However, studies have demonstrated that $\mathrm{IP}_{3} \mathrm{R}$ plays a critical role in regulating the local $\mathrm{Ca}^{2+}$ activity, including the nuclear $\mathrm{Ca}^{2+}$ signaling and affects gene transcription by the nuclear envelop-tethered $\mathrm{IP}_{3} \mathrm{R}-2$ $[17,18]$. This receptor protein is also found in GJs in the ventricular myocardium [20], myoendothelium and sciatic nerve nodes [21,22], but its function in this particular site is not clear, yet. It is noteworthy that both ATP and $\mathrm{IP}_{3}$ can promote intercellular communication in cardiomyocytes [23,24] and non-myocytes [22,25-27]. Additionally, $\mathrm{IP}_{3} \mathrm{R}$ localizes to myoendothelium GJs on the endothelial cell side, but not on the vascular smooth-muscle cell side, leading to selective modulation of GJ coupling on the endothelial cell side by $\mathrm{IP}_{3}[21,27]$, suggesting that local $\mathrm{IP}_{3} \mathrm{R}$ is necessary for $\mathrm{IP}_{3}$-mediated $\mathrm{GJ}$ coupling.

Here, we investigated the potential contribution of GJ $\mathrm{IP}_{3} \mathrm{R}$ to the regulation of $\mathrm{Cx} 43$-associated intercellular communication, and the possible mechanism of this effect in ventricular cardiomyocytes. Because coordinated $\mathrm{Ca}^{2+}$ transients among connected cells reflect ion (electric) propagation through GJs $[28,29]$, functional evaluation of cell-cell communication was carried out using synchronized $\mathrm{Ca}^{2+}$ transients and dye diffusion through GJs among connecting neonatal rat ventricular myocytes (NRVMs) in culture, an ideal native and non-invasive model for intercellular electrical and metabolic exchange $[9,29]$.
Furthermore, using constructed site-directed mutagenesis we mutated $\mathrm{Cx} 43$ phosphorylation sites, to investigate target(s) that is likely involved in the $\mathrm{IP}_{3} \mathrm{R}$-associated signal transduction.

\section{Results}

\section{Structural association of $\mathrm{IP}_{3} \mathrm{R}$ with $\mathrm{Cx} 43$ in gap junctions} of ventricular myocytes

To detect the three $\mathrm{IP}_{3} \mathrm{R}$ isoforms that are expressed in neonatal and adult ventricles [16-18], anti-pan- $\mathrm{IP}_{3} \mathrm{R}$ antibodies and anti-Cx43 antibodies were used to co-immunolabel samples. Figure $1 \mathrm{~A}$ and $\mathrm{B}$ show representative interface region (upper panels) and three-dimensional reconstructions of the end-to-end intercalated discs between paired adjoining cardiomyocytes (bottom panels). Obvious co-localization of $\mathrm{IP}_{3} \mathrm{R}$ and $\mathrm{Cx} 43$ in GJ plaques (yellow color in upper panels) was observed in neonatal rat (Figure 1A) and adult mouse ventricular tissues (Figure 1B: here we used adult mice, because the $\mathrm{IP}_{3} \mathrm{R}$ distribution at the discs has already been reported in adult rat ventricles [20]). The front face disc view of GJ complexes demonstrated that the neonatal ventricular discs were fewer and smaller in size than those in adult discs, and the $\mathrm{IP}_{3} \mathrm{R}$ partially co-localized with Cx43, in particular in the larger GJs in both neonatal and adult ventricles (bottom panels). To conveniently expressing exogenous Cx43, NRVMs were used and co-immunostained with anti-pan- $\mathrm{IP}_{3} \mathrm{R}$ and anti-Cx43 antibodies. Similar to the neonatal tissue samples, $\mathrm{IP}_{3} \mathrm{R}$ clearly co-localized with $\mathrm{Cx} 43$, but there was still a small fraction of $\mathrm{Cx} 43$ that was not associated with $\mathrm{IP}_{3} \mathrm{R}$ in the GJ plaques of tissues and NRVMs (indicated with white arrows in Figure 1A and C). Additionally, it appears that there was more co-distribution of the two proteins in the total GJs of the neonatal samples than those in the adult samples, a difference likely due to a reduced ${ } P_{3} R$ expression after maturation [17-19].

Furthermore, a co-immunoprecipitation assay demonstrated that $\mathrm{IP}_{3} \mathrm{R}$ was detected in the $\mathrm{Cx} 43 \mathrm{co}$ immunoprecipitated complex, and $\mathrm{Cx} 43$ (three bands around $41-45 \mathrm{kDa}$ ) was detectable in the reverse coimmunoprecipitation complexes from NRVMs by antibodies against pan-IP ${ }_{3} R$, or anti-IP ${ }_{3} R-1, I_{3} R-2$ or $I_{3} R-3$ isoforms (Figure 1D). In adult mouse ventricular samples, a detectable $I_{3} R$ signal was also found in the $\mathrm{Cx} 43$ co-immunoprecipitated complexes, but $\mathrm{Cx} 43$ labeling was not detected in the complex co-immunoprecipitated respectively by two anti-pan-IP ${ }_{3} \mathrm{R}$ antibodies recognizing different section of amino acids (see Methods, Figure 1E). This partial difference, which is also consistent with the co-immunostaining assay (Figure $1 \mathrm{~A}$ and $\mathrm{B}$ ), between NRVMs and adult ventricular samples is likely because of lower $\mathrm{IP}_{3} \mathrm{R}$ expression and association with $\mathrm{Cx} 43$ in adult ventricles than in NRVMs. 

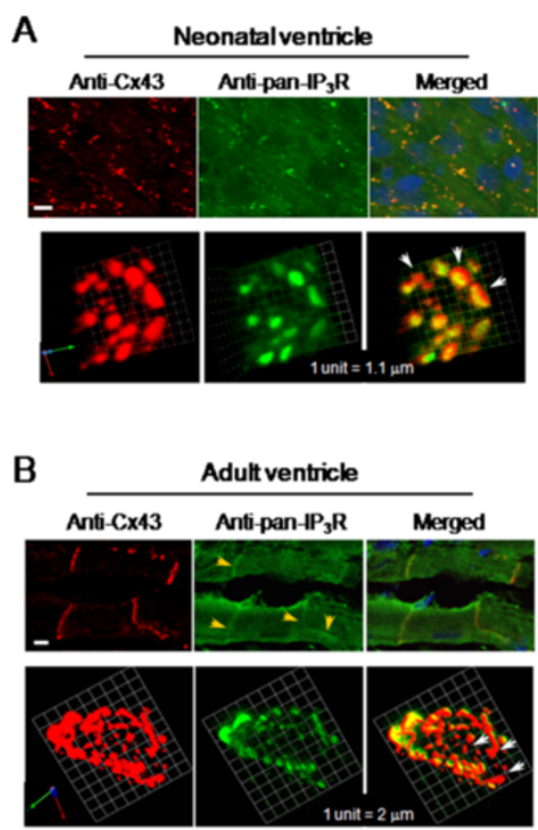
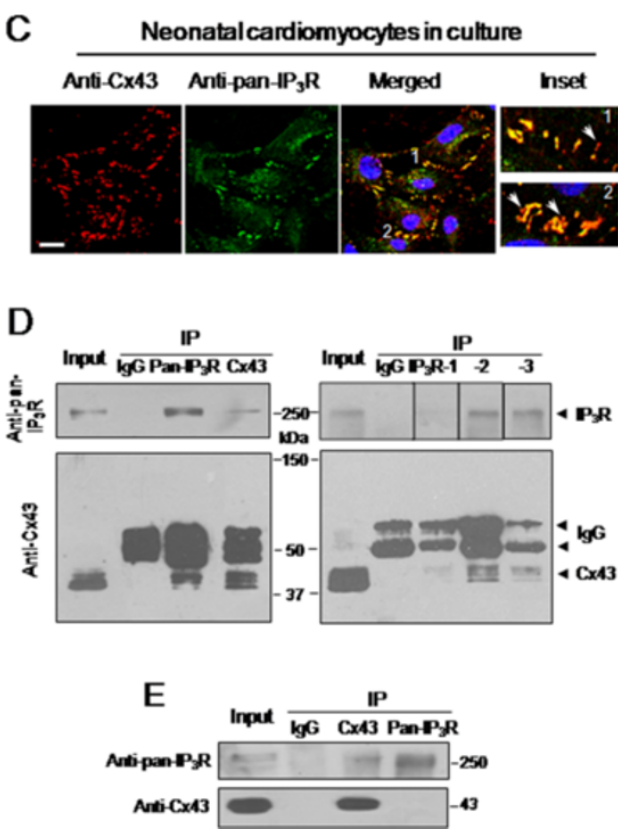

Figure 1 Co-localization of $\mathrm{IP}_{3} \mathrm{R}$ with $\mathrm{Cx} 43$ in gap junctions of ventricular myocytes. Neonatal rat (A) and adult mouse ventricle tissues (B), and cultured NRVMs (C) were co-immunostained with anti-CX43 and anti-pan-IP ${ }_{3} R$ antibodies. Representative confocal images show the subcellular distributions of $\mathrm{C} \times 43$ (red), pan- $\mathrm{P}_{3} \mathrm{R}$ (green) and their co-localization (yellow) in the interfaces between adjacent myocytes. Three-dimensional reconstructions of a single disc of the end-to-end cells display that $\mathbb{P}_{3} R$ partially co-localized with $C \times 43$ in GJs in ventricles (bottom panels in $\mathbf{A}$ and $\mathbf{B}$ ). The enlarged interfaces 1 and 2 (inset in C) show the overlapped distribution of $\mathrm{PP}_{3} R$ and Cx43 in NRVMs. Nucleus was stained with Hoechst 33258 (1 $\left.\mu \mathrm{g} / \mathrm{ml}\right)$. Scale bar: $10 \mu \mathrm{m}$. The yellow and white arrows in all panels indicate the enhanced $I P_{3} R$ signal in ventricles, and a fraction of $C \times 43$ that is not associated with $\mathrm{P}_{3} R$ in GJs of connected NRVMs, respectively. Solubilized lysates from homogenized NRVMs (D) and mouse ventricles (E) were subjected to immunoprecipitation with anti-Cx43, anti-pan- $-P_{3} R$, or anti-I $P_{3} R$ isoform antibodies as indicated. Representative western blots show the co-immunoprecipitated $\mathrm{C} \times 43$ or $\mathrm{IP}_{3} \mathrm{R}$ probed with anti-Cx43 or anti-pan- $\mathrm{P}_{3} \mathrm{R}$ antibody. Data in all panels are representatives of 3-5 independent experiments.

\section{$\mathrm{IP}_{3} \mathrm{R}$-associated regulation of intercellular chemical exchange in ventricular myocytes}

To explore the possible regulatory effect of $\mathrm{IP}_{3} \mathrm{R}$ on $\mathrm{GJ}$ coupling, the intercellular chemical exchange in response to the $\mathrm{IP}_{3} \mathrm{R}$ agonists, myo-inositol 1,4,5-trisphosphate hexakis (butyryloxymethyl) ester $\left(\mathrm{IP}_{3} / \mathrm{BM}\right)$ and $\mathrm{ATP}$, and the $\mathrm{IP}_{3} \mathrm{R}$ antagonist, 2-aminoethoxydiphenyl borate (2-APB), was examined using the FRAP method [30-32]. For comparison, the GJ uncouplers, heptanol $(1 \mathrm{mM})$ and Gap $27(300 \mu \mathrm{M})$, a peptide that mimics short sequences in the extracellular loop 2 of $\mathrm{Cx} 43$ and inhibits GJs directly and specifically $[33,34]$, were also used. In an NRVM monolayer loaded with 6-carboxyfluorescein diacetate (6-CFDA), a cell was selected and bleached with a strong laser light (Figure 2A, see Methods). The fluorescence recovery in the bleached cell because of free 6-CFDA diffusion through GJs rather than other routes from adjacent cells was calculated and the GJ permeability is represented by two characteristic values: the recovery degree (It/I) and the recovery speed \{comparative fluorescence intensity recovery rate $(\mathrm{CFIRR})=[(\mathrm{It}-\mathrm{I} 0) /(\mathrm{I}-\mathrm{I} 0) \times 100 \%] / \mathrm{t}\}$ as reported with minor modifications [30-32]. Here, I, I0, It and It1/2 stand for the fluorescence intensity at the initial, after bleaching, recovery at 400 seconds and at the time for $50 \%$ recovery, respectively.

Like heptanol and Gap 27, 2-APB significantly suppressed the 6-CFDA recovery in the bleached NRVMs, whereas, $\mathrm{IP}_{3} / \mathrm{BM}$, a membrane permeable $\mathrm{IP}_{3}$ analogue, and ATP augmented the dye diffusion (Figure $2 \mathrm{~B}$ and $\mathrm{C}$ ). Importantly, $\mathrm{IP}_{3} / \mathrm{BM}$ or ATP could restore the reduced $\mathrm{G}$ ) communication by heptanol or Gap 27, but not by 2-APB (Figure 2D and E). Chelating the intracellular $\mathrm{Ca}^{2+}$ with BAPTA/AM $(200 \mu \mathrm{M}$, for 10 minutes $)$ did not affect the dye propagation under the resting state or the promotion effect of $\mathrm{IP}_{3} / \mathrm{BM}$. Thus, these data suggest that the mechanism of the $\mathrm{IP}_{3} \mathrm{R}$-associated regulation of GJ intercellular communication is different from that of gap uncouplers, and this effect of $\mathrm{IP}_{3} \mathrm{R}$ is independent of the internal $\mathrm{Ca}^{2+}$ level.

To further determine the $I P_{3} R$ subtype responsible for this regulation of intercellular communication, we suppressed the expression of $I_{3} R-1, I_{3} R-2$ and $I P_{3} R-3$ with shRNA. After cells were transduced with shRNA against each $\mathrm{IP}_{3} \mathrm{R}$ isoform for 48 hours, NRVMs exhibited approximately $70 \%$ inhibition of the expression of each 


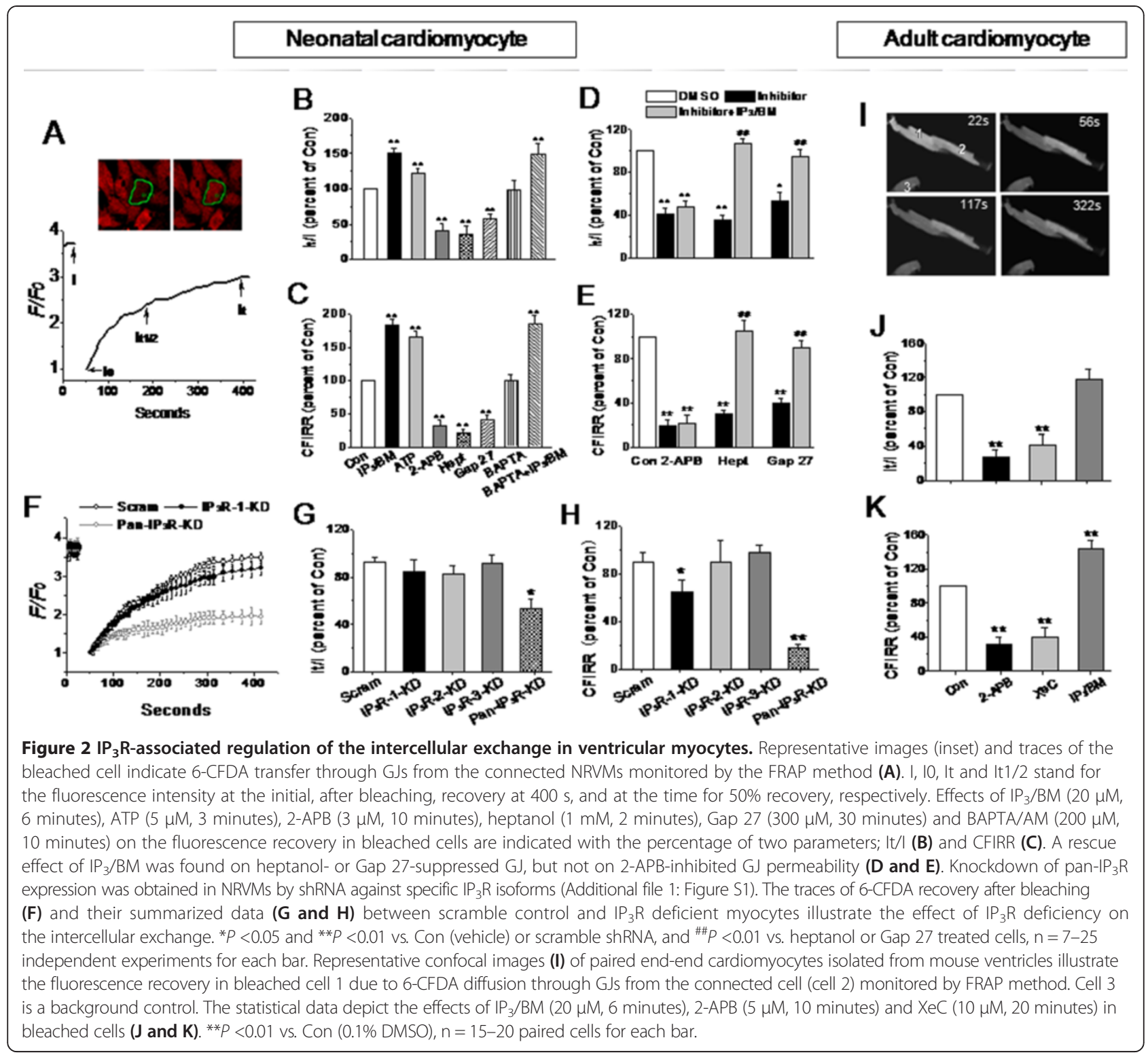

$\mathrm{IP}_{3} \mathrm{R}$ isoform, and a $62 \%$ reduction in relative pan- $\mathrm{IP}_{3} \mathrm{R}$ abundance was observed when the three shRNAs were used together (Additional file 1: Figure S1). A significant reduction in fluorescence recovery was also observed in the bleached pan-IP ${ }_{3} \mathrm{R}-\mathrm{knockdown}$ cells, but not in the $\mathrm{IP}_{3} \mathrm{R}$ isoform-knockdown cells, except for a detectable decrease in the recovery rate observed in $\mathrm{IP}_{3} \mathrm{R}-1$ deficient cells (Figure $2 \mathrm{~F}-\mathrm{H}$ ). This implies that all the three $\mathrm{IP}_{3} \mathrm{R}$ isoforms participate in the regulation on GJ permeability in NRVMs. Again, neither $\mathrm{IP}_{3} / \mathrm{BM}$ nor ATP could rescue the suppressed dye transfer through GJs in pan- $\mathrm{IP}_{3} \mathrm{R}$-knockdwon cells.

Similarly to the neonatal cells, adult paired end-to-end cardiomyocytes exhibited an increased GJ exchange upon $\mathrm{IP}_{3} \mathrm{R}$ activation with $\mathrm{IP}_{3} / \mathrm{BM}(20 \mu \mathrm{M}$, for 10 minutes $)$ and a decreased GP exchange upon $\mathrm{IP}_{3} \mathrm{R}$ blockade with either 2-APB ( $5 \mu \mathrm{M}$, for 10 minutes) or an another inhibitor of $\mathrm{IP}_{3} \mathrm{R}$ xestospongin (XeC $10 \mu \mathrm{M}$, for 20 minutes), as assessed by the FRAP method (Figure 2I-K).

\section{$\mathrm{IP}_{3} \mathrm{R}$-associated regulation of intercellular electrical} spreading in ventricular myocytes

Next, the electrical spreading between adjacent cells was determined by assessing the coordination of spontaneous $\mathrm{Ca}^{2+}$ transients in monolayer NRVMs, because a direct linkage between GJs and coordinate $\mathrm{Ca}^{2+}$ transients have been identified $[28,29]$. Normally, all connected NRVMs oscillate simultaneously because of direct ion propagation through GJs, but this coupling property can be disrupted by GJ inhibition, causing desynchronized $\mathrm{Ca}^{2+}$ transients. 
Thus, the asynchronous $\mathrm{Ca}^{2+}$ oscillations among four to five adjacent cells represent a non-invasive interruption of electrical propagation through GJs, which is expressed as a percentage of the total transients during a 2-minute recording. As shown in Figure $3 \mathrm{~A}-\mathrm{C}$, coordinated $\mathrm{Ca}^{2+}$ transients were discontinued by addition of the gap uncoupler, heptanol or Gap 27, and changed to asynchronous $\mathrm{Ca}^{2+}$ spiking. 2-APB $(3 \mu \mathrm{M})$ that inhibited the 6-CFDA diffusion (Figure $2 \mathrm{~B}$ ) also interfered with the coordination rhythm of $\mathrm{Ca}^{2+}$ transients. Similarly, knocking down pan- $\mathrm{IP}_{3} \mathrm{R}$ expression, but not any $\mathrm{IP}_{3} \mathrm{R}$ isoform, with shRNA caused partial desynchronization of the rhythmic $\mathrm{Ca}^{2+}$ oscillations. Moreover, consistent with the FRAP assay results, $\mathrm{IP}_{3} / \mathrm{BM}$ and $\mathrm{ATP}$ resynchronized these distorted $\mathrm{Ca}^{2+}$ transients in heptanol- or Gap 27-treated cells (Figure 3B and Additional file 2: Video 1), but not in 2-APB- (Figure 3C and Additional file 3: Video 2) or pan- $\mathrm{IP}_{3} \mathrm{R}$ shRNA-treated cells (Figure 3D). Neither isoprenaline, which stimulates the $\beta_{1}$-adrenergic receptor, nor phorbol myristate acetate (PMA), which activates $\mathrm{PKC}$, mimicked this recovery effect of $\mathrm{IP}_{3} / \mathrm{BM}$.
Furthermore, nifedipine, which inhibits L-type $\mathrm{Ca}^{2+}$ channels, did not elicit any uncoupling effect on $\mathrm{Ca}^{2+}$ oscillations (Figure 3B,C and E), although all of these reagents did affect the $\mathrm{Ca}^{2+}$ signaling rate and amplitude (Figure 3E, data not completely shown).

\section{$\mathrm{IP}_{3} \mathrm{R}$-associated regulation of $\mathrm{C} \times 43$ phosphorylation in ventricular myocytes}

Compared with other connexins, $\mathrm{Cx} 43$ has a larger intracellular C-terminal tail, and (de)phosphorylation of serines in this domain represents an important regulatory mechanism for GJ gating, assembly, trafficking, and degradation. To investigate whether $\mathrm{IP}_{3} / \mathrm{IP}_{3} \mathrm{R}$ pathway affects $\mathrm{GJ}$ permeability by mediating the $\mathrm{Cx} 43$ phosphorylation, the relative abundance of pS262, pS368, and pS279/282 was analyzed by western blot analysis using phospho-specific antibodies. While one band of about $43 \mathrm{kDa}$ appeared with the pS262 or pS368 antibody labeling, two clear bands were detected with the pS279/282 antibody labeling of samples from both NRVMs and adult ventricles (Figure 4A). Activation of PKC with PMA caused a

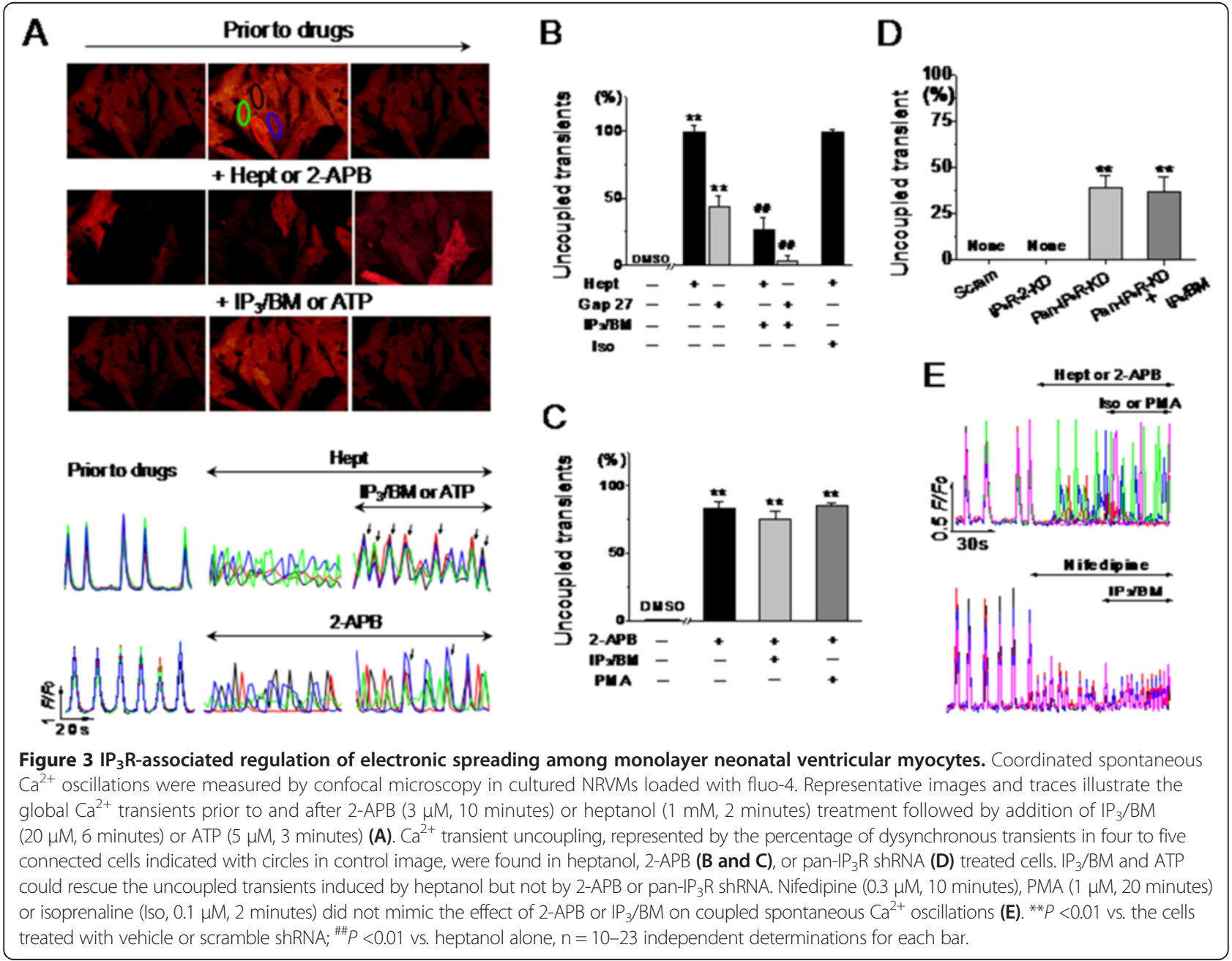




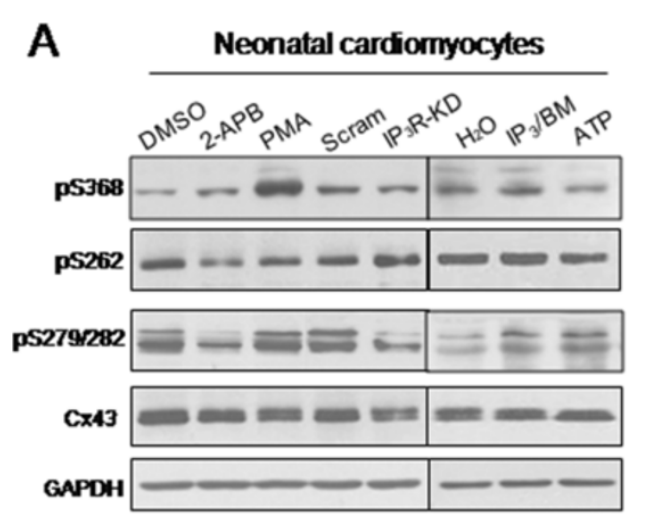

B
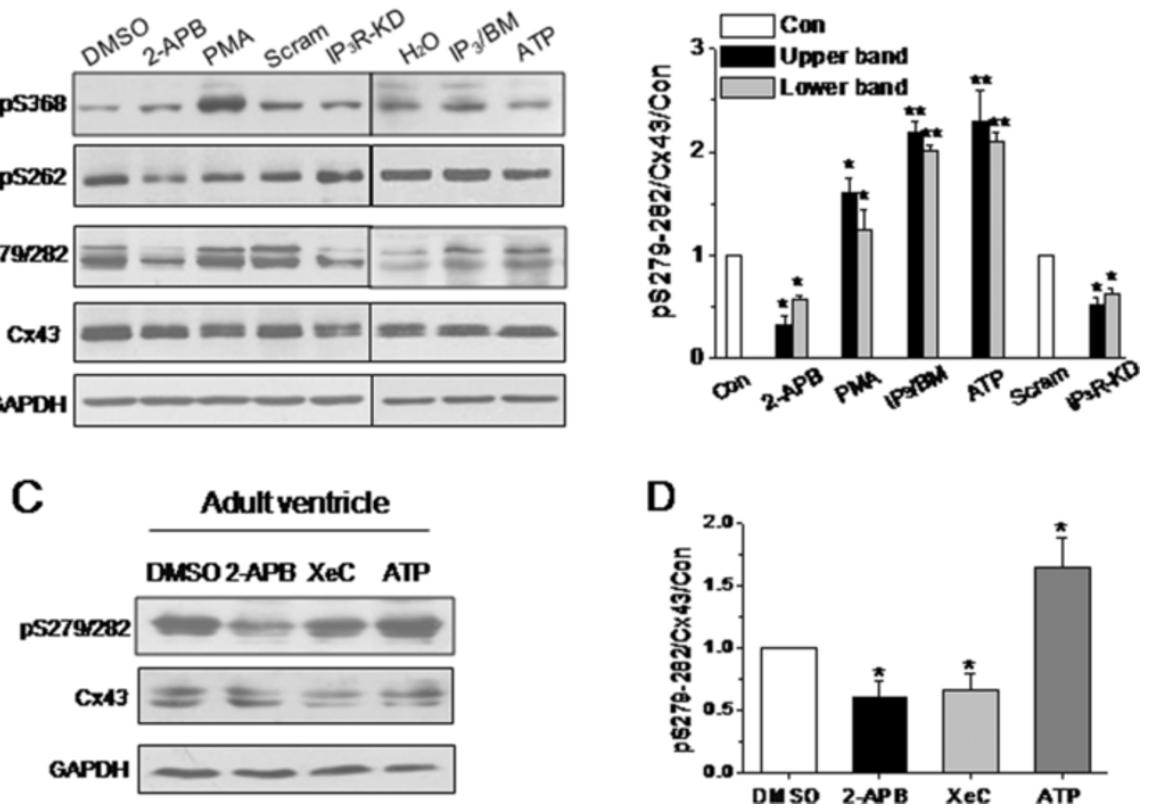

Figure $4 \mathrm{IP}_{3} \mathrm{R}$-associated regulation of $\mathrm{Cx} 43$ phosphorylation in ventricular cardiomyocytes. Solubilized lysates from homogenized NRVMs (A) and mouse ventricles (C) that had been treated with different reagents as indicated were subjected to specific anti-phosphor Cx43 and anti-CX43 antibodies, respectively. Representative western blots of pS368, pS262, pS279/282 and Cx43 as indicated (A) and their normalized relative abundances in NRVMs (B), and the blots of pS279/282 and CX43 (C) and their normalized data in adult ventricles (D) depict the effects of 2-APB, shRNA against pan- $\mathrm{P}_{3} \mathrm{R}, \mathrm{IP}_{3} / \mathrm{BM}$ and ATP at the concentrations similar to those in functional evaluation on $\mathrm{C} \times 43$ phosphorylation. ${ }^{*} P<0.05$ and ${ }^{* *} P<0.01$ vs. DMSO- or scramble shRNA-treated cells, $n=3-4$ independent experiments for each bar.

significant increase in S368 phosphorylation and a slight increase in S279/282 phosphorylation, which is consistent with previous reports [10,12]. However, interestingly, inhibition of $\mathrm{IP}_{3} \mathrm{R}$ with 2 -APB $(3 \mu \mathrm{M})$ or shRNA against pan- $\mathrm{IP}_{3} \mathrm{R}$ significantly suppressed the levels of S279/282 phosphorylation, while no significant change was observed in S262 or S368 phosphorylation (Figure $4 \mathrm{~A}$ and $\mathrm{B}$ ). Furthermore, activation of $\mathrm{IP}_{3} \mathrm{R}$ with $\mathrm{IP}_{3} / \mathrm{BM}(20 \mu \mathrm{M})$ or ATP $(5 \mu \mathrm{M})$ promoted Cx43 phosphorylation at S279/282 in NRVMs, and similar results were obtained in adult ventricles that were retrogradely perfused in a Langendorff system with HEPES-buffered Tyrode solution containing 2-APB, $\mathrm{XeC}$, or ATP for 10,20 , or 5 minutes, respectively (Figure $4 \mathrm{C}$ and $\mathrm{D}$ ).

\section{Effects of S279 and S282 mutations on Cx43-assciated junction coupling in ventricular myocytes}

To elucidate whether S279/282 phosphorylation affects the gap permeability in cardiomyocytes, we used site-directed mutagenesis to mutate S279 and S282 into alanine or aspartic acid in rat $C x 43$ gene (wt-Cx43). Compared with the vector control, transduction of adenovirus carrying S279A (5 m.o.i.), S282A (2 m.o.i.), S282D (2 m.o.i.), or wt-Cx43 (20 m.o.i.) into monolayer NRVMs generally caused similar increases in Cx43 expression and S279/282 phosphorylations in all groups of cells, except for a reduced S279/282 phosphorylation in S282A- (Figure 5A and B) and S279A/282A-transduced myocytes (data not shown). To avoid the infection efficiency differences among different groups, lucifer yellow (LY), a GJ-permeable but membrane-impermeable dye, combined with dextranrhodamine B, a GJ- and membrane-impermeable dye, were used to evaluate the GJ permeability in monolayer NRVMs $[35,36]$. We found that all living cells were impermeable to dextran-rhodamine B, but permeable to LY with different efficiencies. Cells expressing the S279A mutant, S282D mutant, or wt-Cx43 exhibited intact synchronous $\mathrm{Ca}^{2+}$ oscillations and elevated LY uptake compared with vector-treated cells, whereas cells expressing the S282A mutant displayed uncoordinated $\mathrm{Ca}^{2+}$ spiking and decreased LY uptake (Figure 5C-E). Identical results were also found in the cells with double mutations of S279 and S282 (data not shown). Immunostaining assay with anti-Cx43 antibody confirmed that significantly more $\mathrm{Cx} 43$ was found on the cell membrane of all Cx43-modified cells compared with untreated control cells (bottom images in Figure 5C). To exclude the possibility that Cx43-S282A does not form GJ plaques [37], thereby causing suppression of the intercellular permeability compared with those in 


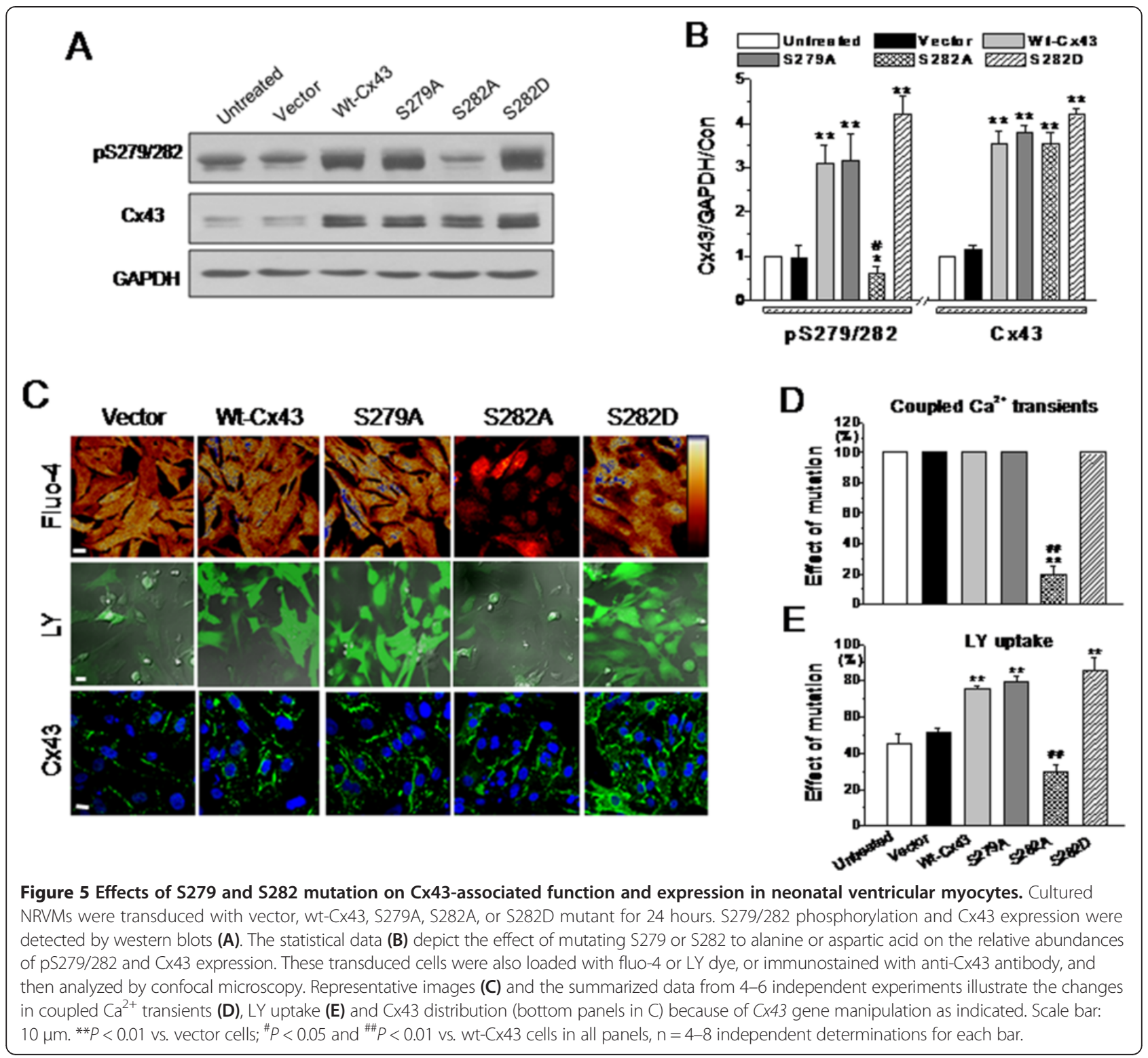

other Cx43-maniputated cells, the relative abundance of Cx43 expression in NRVMs was further determined by western blotting of triton-insoluble and -soluble fractions, a method used to distinguish between GJs and GJ precursors [13,38], after knockdown of endogenous Cx43 expression by specific siRNA [38]. There was no significant difference in both $\mathrm{Cx} 43$ fractions between the cells treated with wt-Cx43 or S282A (Figure 6A and B), but much lowered pS279/282 level in S282A cells than in wtCx43 cells, indicating that Cx43-S282A, like wt-Cx43, was able to dock in the GJ plaques in cardiomyocytes, but was unable to efficiently couple the intercellular communication. Furthermore, immunostaining assay with anti-HA antibody was used to confirm that exogenous $\mathrm{Cx} 43$ did distribute on the cell membrane of the Cx43-modified cells (Figure 6C).
To further determine the role of S279/282 phosphorylation in the regulation of GJ permeability, HEK293 cells (they also possess 2-APB-sensitive endogenous Cx43 [39]) expressing the abovementioned mutants were used to determine the differences in exogenous Cx43 phosphorylation on S279/282 and in GJ permeability. Interestingly, only cells transduced with the S279A/282A mutant failed to increase the Cx43 expression, while all the other cells treated with wt-Cx43, S279A, or S282A mutant displayed elevated S279/282 phosphorylation and Cx43 expression, which was distributed in the cytosol and on the cell surface (Figure 7A-C). Consistently, functional evaluation of GJ permeability showed a linkage of LY uptake with the increased Cx43 phosphorylation on S279/282 and exogenous $\mathrm{Cx} 43$ expression, and that $5 \mu \mathrm{M} 2-\mathrm{APB}$ 

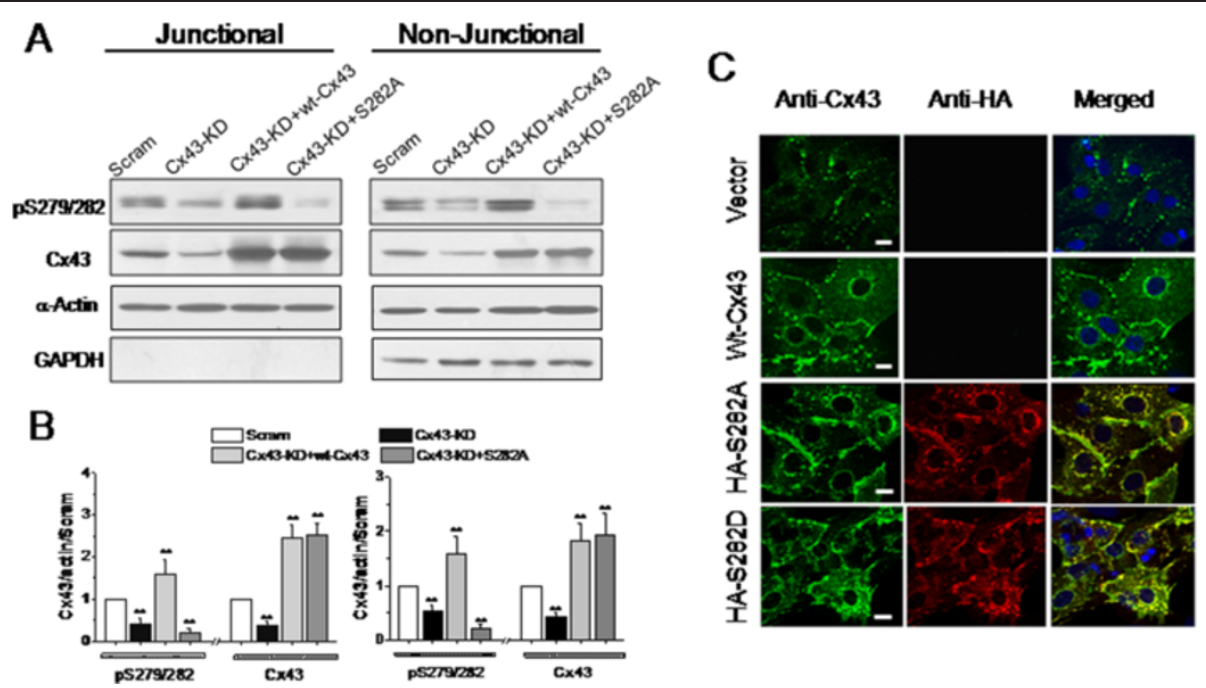

Figure 6 Effect of S282 mutation on Cx43 expression in endogenous Cx43-knockdown neonatal ventricular myocytes. NRVMs were transduced with scramble or siRNA to knockdown Cx43 (Cx43-KD, m.o.i. $=60)$ for 48 hours followed by further exposure of wt-Cx43 (m.o.i $=20)$ or S282A mutant (m.o.i. $=2$ ) for 24 hours. The pS279/282 levels in triton X-100 soluble and insoluble fractions was determined by western blot (A), and normalized by the level of actin and then the level of Cx43 in scramble cells (B). The detection of GAPDH observed in non-junctional but not in junctional fraction represents a successful separation of non-junctional and junctional $C \times 43$. N = 4 independent determinations for each bar, and ${ }^{* *}$ denotes $P<0.01$ vs. scramble cells. Cultured NRVMs were co-immunostained with anti-Cx43 and anti-HA-probe antibodies after transduced with scramble, wt-Cx43 (m.o.i = 20), S282A-HA (m.o.i = 2), or S282D-HA mutant ( $m .0 . i=2)$ for 24 hours $(\mathbf{C})$. Representative confocal images show the subcellular distributions of total Cx43 (green), exogenous Cx43-HA (red) and their co-localizations in S282D-HA and S282A-HA cells (yellow). Scale bar: $10 \mu m$.

abrogated the S279/282 phosphorylation as well as the LY uptake in the control and all the Cx43-manipulated HEK293 cells (Figure 7D).

\section{Discussion}

In this study, we demonstrated, for the first time, that the $\mathrm{IP}_{3} \mathrm{R}$-associated signaling pathway regulates GJ intercellular communication by affecting Cx43 phosphorylation on S279/S282 in ventricular myocytes, and that the changes in the internal $\mathrm{Ca}^{2+}$ level are probably not involved.

Many studies have demonstrated that G-protein coupled receptor (GPCR) activators including noradrenaline, ATP and vasopressin can promote GJ intercellular communication in cardiomyocytes and non-myocytes [21-26], whereas $\mathrm{IP}_{3} \mathrm{R}$ inhibition by 2-APB interferes with the intrinsic cell-cell communication [38,39]. Therefore, $\mathrm{IP}_{3}$ and ATP due to their rapid free diffusion through GJ channels have been proposed as important molecules for synchronizing $\mathrm{Ca}^{2+}$ signaling between adjacent cells in GPCR pathway activation [22-25]. However, there was no information on whether the localized $\mathrm{IP}_{3} \mathrm{R}$ to GJs is involved in this regulation until it was reported that $I_{3} R-1$, which is selectively localized to the endothelial side of GJs, allows endothelial cells to respond to $\mathrm{IP}_{3}$ from smooth-muscle cells [21,27]. Our data are in good agreement with these findings. Deficiency in pan- $\mathrm{IP}_{3} \mathrm{R}$ expression led to reduced gap permeability and induction of uncoordinated $\mathrm{Ca}^{2+}$ transients in cardiomyocytes (Figures 2 and 3). More importantly, $\mathrm{IP}_{3} / \mathrm{BM}$ selectively restored the blocked GJ permeability and asynchronous $\mathrm{Ca}^{2+}$ transients by heptanol or Gap 27, but not by interference with $\mathrm{IP}_{3} \mathrm{R}$ by 2 -APB or shRNA, indicating that this action of $\mathrm{IP}_{3}$-associated signaling occurs on the site of GJ plaques rather than on the sarcoplasmic reticulum stores. Additionally, the physical association between $\mathrm{IP}_{3} \mathrm{R}$ and $\mathrm{Cx} 43$ in the GJs and the alterations in Cx43 phosphorylation confer the possibilities of their molecular interactions directly or indirectly, and thus affecting the Cx43 function (Figure 1).

Cx43 has a large C-terminus domain in the cytosol, allowing it to interact with other proteins including kinases, phosphatases, membrane receptors, cell signaling and scaffolding proteins [9-15]. It is well recognized that phosphorylation of different $\mathrm{Cx} 43$ residues in the C-terminal leads to distinguishable changes in Cx43 properties including GJ gating, Cx43 assembly, trafficking, and degradation $[1,13-15,37]$. It has also been shown that Cx43 phosphorylation on one residue sometimes affects Cx43 interactions with other partner proteins or phosphorylation of another site [40,41]. S279 and S282 residues together with S255 and S262 have been identified as the recognition sites for the MAPK signaling pathway, which can promote their phosphorylations and induce a decreased conductivity of GJs in several cell lines $[11,12,14]$. However, the specific effect of the S279/282 sites on the acute regulation of GJ intercellular communication is rather sparse and obscure. It appears that MAPK is necessary but not sufficient to lead acute closure of GJ 


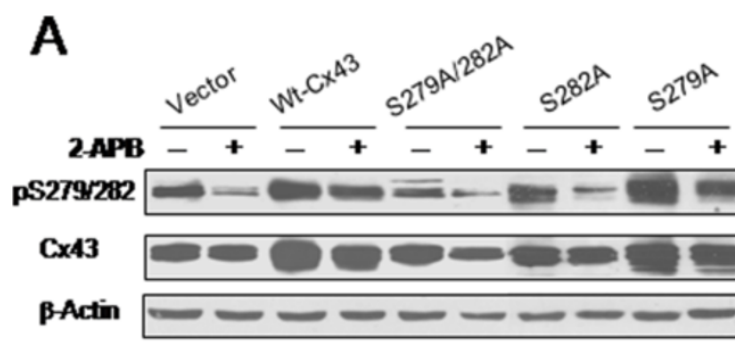

B
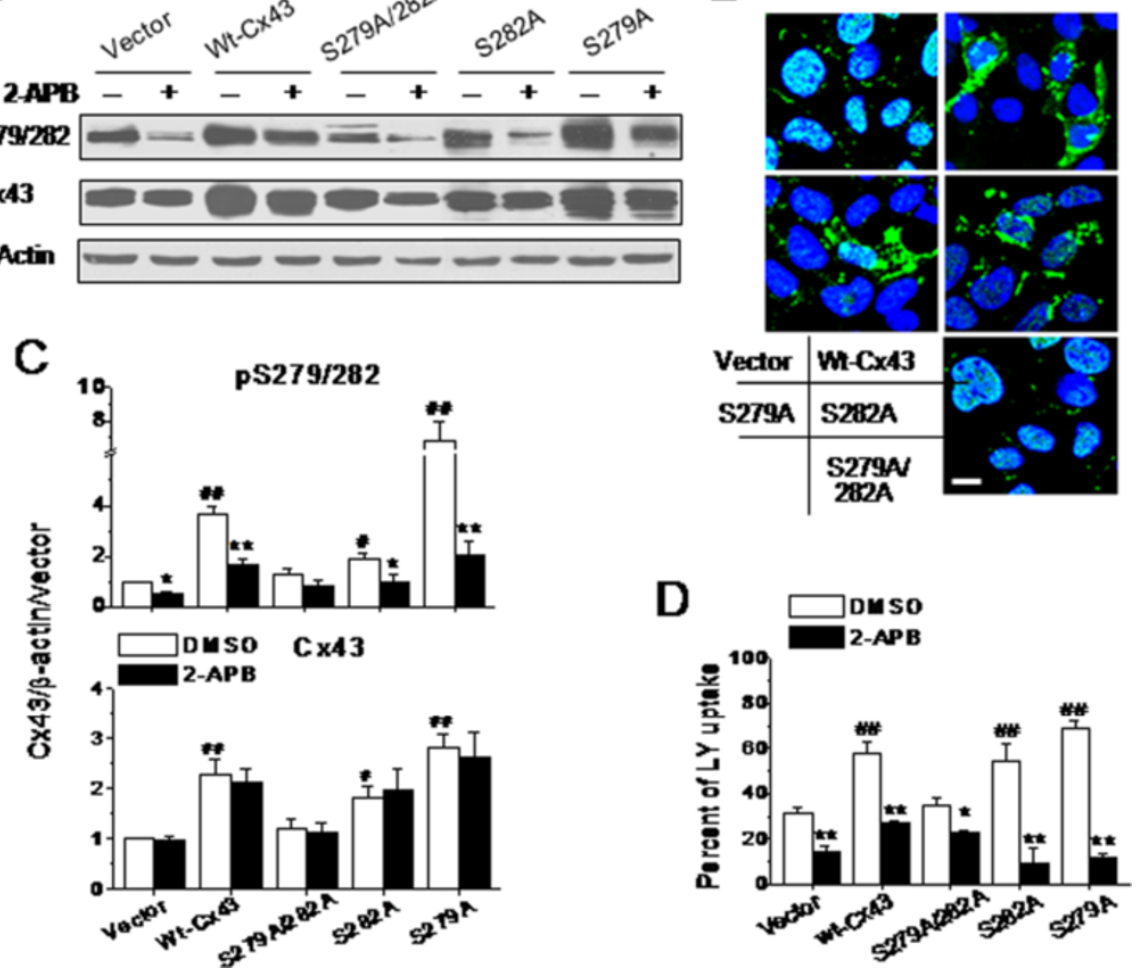

Figure 7 Effects of S279 or S282 mutation on Cx43 expression and gap junction permeability in non-muscle cells. Representative western blots of lysates from HEK293 cells (A), which had been transduced with plasmids carrying rat nonspecific sequence (vector), wt-Cx43, S279A, S282A or S279A/282A genes for 48 hours, show the changes in the relative levels of pS279/282 and Cx43 expressions due to the mutations. Here, one blot membrane with 6 left bands and another membrane with 4 right bands from the same lysates were connected together to show all treatment groups. Some groups of the HEK293 cells were also treated with $5 \mu \mathrm{M}$ 2-APB for 10 minutes, while others were stained with anti-Cx43 antibody to examine the subcellular distribution of Cx43 upon different treatments as indicated (B). Scale bar: $10 \mu \mathrm{m}$. The statistical data normalized by $\beta$-actin depict the effects of different Cx43 mutants and 2-APB on S279/282 phosphorylation and Cx43 expression (C). N=4 independent determinations for western blotting and immunostaining tests, respectively. In addition, the statistical data of LY uptake depict the effects of the different mutants on GJ permeability (D). $N=5-6$ independent determinations for each bar. ${ }^{*} P<0.05$ and ${ }^{* *} P<0.01$ vs. DMSO $(0.1 \%) ;{ }^{\#} P<0.05$ and $\# P<0.01$ vs. vector, respectively.

channels, and that other pathways including PKC activation are converged to regulate Cx43 coupling in response to various growth factors and v-Src activation $[12,14]$. However, Warn-Cramer, et al. have reported that activation of MAPK and the following phosphorylation of Cx43 at the site(s) of S279 and/or S282 was sufficient to disrupt GJ communication in Hela cells, a conclusion mainly based on that cells with S255A, S279A, and S282A Cx43 mutations failed to close GJs in response to MAPK activation, whereas the S255D Cx43 mutant established a level of GJ coupling comparable to that observed in cells expressing wt-Cx43 [11]. These conflict results reflect the complexity and diversity of $\mathrm{Cx} 43$ phosphorylation on multiple sites at same time upon activation of a signal pathway or a kinase, and thus diversified regulation of GJ function $[1,15]$.

The data in this study demonstrated that a decrease in endogenous Cx43 phosphorylation on S279/282 down-regulated, whereas an increase in their phosphorylation up-regulated the basal GJ communication in cardiomyocytes (Figure 4). Exogenous expression of S279A, S282A or S282D in cardiomyocytes and HEK293 cells showed a close association between S279/282 phosphorylation and gap permeability (Figures 5 and 7). The accordant responses of Cx43 phosphorylation on S279 and S282 to $\mathrm{IP}_{3} / \mathrm{IP}_{3} \mathrm{R}$ signaling pathway and to mutation at S279 or S282 is specific by already ruling out some other possible interfering factors, such as intracellular $\mathrm{Ca}^{2+}$ change or non-specificity of the antibody, because 1) nifedipine which also altered internal $\mathrm{Ca}^{2+}$ signaling in NRVMs (Figure 3) did not affect Cx43 phosphorylation on S279/282 (data not shown); 2) S262 phosphorylation remained unaltered to changes in $\mathrm{IP}_{3} \mathrm{R}$ function status (Figure 4) or to S282A or S282D mutant treatment (data not shown); and 3) the detection of Cx43 in S282A-HA-treated cells with anti-HA antibody indicates that exogenous $\mathrm{Cx} 43$ was expressed in 
the site of GJs (Figure 6), thereby contribute for the distorted GJ function in these mutant-transduced cells (Figure 5). However, it is not clear about the ratio of exogenous Cx43 abundance among the total in one particular mutant, since it is hard to separate the exogenous protein from the endogenous protein in one blotting membrane simply by using anti-HA and anti-Cx43 antibodies. Therefore, these data here demonstrated a close link between $\mathrm{IP}_{3} / \mathrm{IP}_{3} \mathrm{R}$ pathway and $\mathrm{Cx} 43$ phosphorylation on S279/282, and also strongly suggest an important role of their phosphorylation in the regulation of Cx43-associated function.

Although S282A mutant, but not S279A mutant, suppressed both dye diffusion and coupled $\mathrm{Ca}^{2+}$ oscillations through GJs, it appears that failure to phosphorylate S282 also affected the phosphorylation of S279, because no further S279/282 phosphorylation above baseline was observed in S282A-treated cardiomyocytes (Figure 5), but an elevation in S279/282 phosphorylation and inhibitory effect of 2-APB on S279/282 phosphorylation and LY uptake were observed in S282A-treated-HEK293 cells (Figure 7). Additionally, S282A-mutated cardiomyocytes (Figure 5) showed exactly the same effects on LY uptake and $\mathrm{Ca}^{2+}$ coordination as those observed in S279/282mutated cardiomyocytes (data not shown) and HEK293 cells (Figure 7). Thus, the site of S279 cannot be excluded from the regulatory role of S279/282 phosphorylation in GJ communication. It is also noticeable that unlike the observation in S282A-treated cardiomyocytes that did express the exogenous $\mathrm{C} x 43$ (Figure 6), the expression of the rat Cx43-S279/282 mutant in HEK293 cells failed to induce additional $\mathrm{Cx} 43$ expression, but the other mutants did (Figure 7). A similar observation has been reported in ovarian granulosa, in which the S279/282 mutants were confined to intracellular sites, with few GJs [37]. However, a different effect of S279/282 phosphorylation has been demonstrated to disrupt GJ assembly by triggering endocytosis of $\mathrm{Cx} 43$ prior to its assembly in pancreatic cancer cells [42]. Nevertheless, all the results suggest the important role of S279/282 phosphorylation in the regulation of $\mathrm{Cx} 43$ assembly/expression in non-myocytes.

Therefore, this study showed that the $\mathrm{IP}_{3} / \mathrm{IP}_{3} \mathrm{R}$ pathway links with Cx43 phosphorylation on S279/ 282, providing a simple but rather rapid regulation for GJ coupling. In particular, this association is probably necessary for cardiac performance during sympathetic nervous activation of both $\alpha_{1}$ - and $\beta_{1}$-adrenergic receptors. The formation of $\mathrm{IP}_{3}$ and activation of GJ IP ${ }_{3} \mathrm{R}$ consequently induces a prompt elevation in intercellular coupling to match the accelerated electric triggering and myocardium contraction by $\beta_{1}$-receptor stimulation. It is not clear, yet, how $\mathrm{IP}_{3} \mathrm{R}$ interacts with $\mathrm{Cx} 43$ and affects $\mathrm{Cx} 43$ phosphorylation on $\mathrm{S} 279 / 282$. As $\mathrm{IP}_{3} / \mathrm{BM}$ and the deficiency in $\mathrm{IP}_{3} \mathrm{R}$ expression efficiently induced obvious changes in $\mathrm{Cx} 43$ phosphorylation and in regulation of gap permeability, PKC and MAPK are probably not the signaling molecules in this regulation. Some studies have demonstrated that sodium channels also co-localize with Cx43 in GJs, but their function is unknown [43-45]. Therefore, further studies are needed to define how $\mathrm{IP}_{3} \mathrm{R}$ interacts with $\mathrm{Cx} 43$ and regulates its phosphorylation, which may provide a clue for interpreting how an ion channel interacts with connexins.

\section{Conclusions}

Taken together, these observations demonstrate that $\mathrm{IP}_{3} \mathrm{R}$ regulates $\mathrm{Cx} 43$-associated intercellular communication in a manner independent of internal $\mathrm{Ca}^{2+}$ change, but rather reflecting a physiological role of $\mathrm{IP}_{3} \mathrm{R}$ interaction with $\mathrm{Cx} 43$, thereby regulating Cx43 phosphorylation on S279/282 in ventricular myocytes.

\section{Methods}

This study was approved by the Capital Medical University Animal Care and Use Committee, and all studies were conducted in accordance with "Guide for the Care and Use of Laboratory Animals" adopted by the Beijing Government and "Guide for the Care and Use of Laboratory Animals" published by the US National Institutes of Health (publication No. 85-23, revised 1996).

The full Methods section refers to the Additional file 4 .

\section{Additional files}

Additional file 1: Figure S1. Evaluation of interfering $I P_{3} R$ isoform and pan- $I P_{3} R$ expression with shRNA. Representative western blots of knockdown of $I P_{3} R$ isoform or pan- $P_{3} R$ in cultured NRVMs by shRNA against the distinctive $I_{3} R$ isoform ( $A$ and $B$ ) and pan- $P_{3} R(C)$. The relative abundances of each isoform $I_{3} R$ and pan-IP $R$ were normalized by GAPDH and then scramble control. ${ }^{* *} P<0.01, n=3-5$ independent experiments for each panel.

Additional file 2: Video1. The interrupted coordination in NRVM $\mathrm{Ca}^{2+}$ transients induced by heptanol (1 $\mathrm{mM}, 2$ minutes) is recovered by ATP (5 $\mu \mathrm{M}, 2$ minutes).

Additional file 3: Video2. The interrupted coordination in NRVM $\mathrm{Ca}^{2+}$ transients induced by 2 -APB ( $3 \mu \mathrm{M}, 6$ minutes) could not be rescued by ATP $(5 \mu \mathrm{M}, 2$ minutes).

Additional file 4: Full Methods.

\section{Abbreviations}

IP $R$ : Inositol 1,4,5-trisphosphate receptor; LY: Lucifer yellow; Cx43: Connexin 43; NRVMs: Neonatal rat ventricular myocytes; FRAP: Fluorescence recovery after photobleach; HBSS: HEPES-buffered salt solution; XeC: Xestospongin C; 2-APB: 2-aminoethoxydiphenyl borate; 6-CFDA: 6-carboxyfluorescein diacetate; ER: Endoplasmic reticulum; SR: Sarcoplasmic reticulum; S279/282: Serines 279/282; S279A/282A: Serine 279 and serine 282 with alanine; S282D: Serine 282 with aspartic acid; GPCR: G-protein coupled receptor; GAPDH: Glyceraldehyde-3-phosphate dehydrogenase.

\section{Competing interests}

The authors declare that they have no competing interests. 


\section{Authors' contributions}

$\mathrm{DL}$ designed and conceived most of the experiments and drafted the manuscript; MK and NL respectively performed most of experiments; $C L, J D$ $X Y, O Y$ and $C Z$ participated in the experiment of adult cardiomyocytes; $\mathrm{QM}$ and $Y Z$ analyzed data; $J H$ participated in the mutation experimental design and analysis. All authors read and approved the final manuscript.

\section{Acknowledgements}

This work was supported by grants from National Natural Science Foundation (81370339, 30973537), Beijing National Natural Science Foundation (5122006) and Beijing Key Laboratory of Cardiovascular Diseases Related to Metabolic Disturbance (Z13111000280000). We thank Dr. Heping Cheng from Institute of Molecular Medicine, Peking University for helpful discussion and suggestions, and Dr. Qihua He from Medical Center of Peking University for technical support.

\section{Author details}

'Department of Pharmacology, Capital Medical University, Beijing 100069, China. ${ }^{2}$ Institute of Molecular Medicine, Peking University, Beijing 100871, China. ${ }^{3}$ Department of Biochemistry, Capital Medical University, Beijing 100069, China. ${ }^{4}$ Present address: National Institute for Radiological Protection, China CDC, Beijing 100088, China.

Received: 2 December 2013 Accepted: 11 September 2014

Published online: 28 September 2014

\section{References}

1. Giepmans BN: Gap junctions and connexin-interacting proteins. Cardiovasc Res 2004, 62:233-245.

2. Goodenough DA, Paul DL: Beyond the gap: functions of unpaired connexon channels. Nat Rev Mol Cell Biol 2003, 4:285-294

3. Roell W, Lewalter T, Sasse P, Tallinin YN, Choi BR, Breitbach M, Doran R, Becher UM, Hwang SM, Bostani T, von Maltzahn J, Hofmann A, Reining S, Eiberger B, Gabris B, Pfeifer A, Welz A, Willecke K, Salama G, Schrickel JW, Kotlikoff Ml, Fleischmann BK: Engraftment of connexin 43-expressing cells prevents post-infarct arrhythmia. Nature 2007, 450:819-824.

4. Woodcock EA, Reyes N, Jacobsen AN, Du XJ: Inhibition of inositol $(1,4,5)$ trisphosphate generation by endothelin-1 during postischemic reperfusion: A novel antiarrhythmic mechanism. Circ 1999, 99:823-828.

5. Dhein S: Cardiac ischemia and uncoupling: gap junctions in ischemia and infarction. Adv Cardiol 2006, 42:198-212.

6. Laird DW: Life cycle of connexins in health and disease. Biochem J 2006 394:527-543.

7. Wei CJ, Xu X, Lo CW: Connexins and cell signaling in development and disease. Annu Rev Cell Dev Biol 2004, 20:811-838.

8. Dobrowolski R, Willecke K: Connexin-caused genetic diseases and corresponding mouse models. Antioxid Redox Signal 2009, 11:283-295.

9. Yeager M: Structure of cardiac gap junction intercellular channels. J Struct Biol 1998, 121:231-245.

10. Heyman NS, Lampe PD, Janis Burt M: Phosphorylation selectivity of connexin 43 channels is regulated through protein kinase C-dependent phosphorylation. Circ Res 2006, 98:1498-1505.

11. Warn-Cramer BJ, Cottrell GT, Burt JM, Lau AF: Regulation of connexin-43 gap junctional intercellular communication by mitogen-activated protein kinase. J Biol Chem 1998, 273:9188-9196.

12. Solan JL, Lampe PD: Connexin 43 in LA- 25 cells with active V-src is phosphorylated on Y247, Y265, S262, S279/282, and S368 via multiple signaling pathways. Cell Commun Adhes 2008, 15:75-84.

13. Bruce AF, Rothery S, Dupont E, Severs NJ: Gap junction remodelling in human heart failure is associated with increased interaction of connexin43 with ZO-1. Cardiovasc Res 2008, 77:757-765.

14. Lin R, Warn-Cramer BJ, Kurata WE, Lau AF: V-Src phosphorylation of connexin 43 on Tyr247 and Tyr265 disrupts gap junctional communication. J Cell Biol 2001, 154:815-827.

15. Grosely R, Kopanic JL, Nabors S, Kieken F, Spagnol G, Al-Mugotir M, Zach S, Sorgen PL: Effects of phosphorylation on the structure and backbone dynamics of the intrinsically disordered Connexin43 carboxyl-terminal domain. J Biol Chem 2013, 288:24857-24870.

16. Signore S, Sorrentino A, Ferreira-Martins J, Kannappan R, Shafaie M, Ben FD, Isobe K, Arranto C, Wybieralska E, Webster A, Sanada F, Ogórek B, Zheng H, Liu X, del Monte F, D’Alessandro DA, Wunimenghe O, Michler RE, Hosoda T,
Goichberg P, Leri A, Kajstura J, Anversa P, Rota M: Inositol 1, 4, 5-trisphosphate receptors and human left ventricular myocytes. Circ 2013, 128:1286-1297.

17. Wu X, Zhang T, Bossuyt J, Li X, McKinsey TA, Dedman JR, Olson EN, Chen J, Brown JH, Bers DM: Local Ins $\mathrm{P}_{3}$-dependent perinuclear $\mathrm{Ca}^{2+}$ signaling in cardiac myocyte excitation-transcription coupling. J Clin Invest 2006, 116:675-682.

18. Luo D, Yang D, Lan X, Li K, Li X, Chen J, Zhang Y, Xiao RP, Han Q, Cheng H: Nuclear $\mathrm{Ca}^{2+}$ sparks and waves mediated by inositol 1,4,5-trisphosphate receptors in neonatal rat cardiomyocytes. Cell Calcium 2008, 43:165-174.

19. Ju YK, Liu J, Lee BH, Lai D, Woodcock EA, Lei M, Cannell MB, Allen DG: Distribution and functional role of inositol 1,4,5-trisphosphate receptors in mouse sinoatrial node. Circ Res 2011, 109:848-857.

20. Kijima Y, Saito A, Jetton TL, Magnuson MA, Fleischer S: Different intracellular localization of inositol 1,4,5-trisphosphate and ryanodine receptors in cardiomyocytes. J Bio/ Chem 1993, 268:3499-3506.

21. Isakson BE: Localized expression of an Ins $(1,4,5) \mathrm{P}_{3}$ receptor at the myoendothelial junction selectively regulates heterocellular $\mathrm{Ca}^{2+}$ communication. J Cell Sci 2008, 121:3664-3673.

22. Toews JC, Schram V, Weerth SH, Mignery GA, Russell JT: Signaling protein in the axoglial apparatus of sciatic nerve node of Ranvier. Glia 2007 55:202-213.

23. Harrison SN, Autelitano DJ, Wang BH, Milano C, Du XJ, Woodcock EA: Reduced reperfusion-induced Ins(1,4,5)P3 generation and arrhythmias in hearts expressing constitutively active alpha1B-adrenergic receptors. Circ Res 1998, 83:1232-1240.

24. Turner MS, Haywood GA, Andreka P, You L, Martin PE, Evans WH, Webster KA Bishopric $\mathrm{NH}$ : Reversible connexin 43 dephosphorylation during hypoxia and reoxygenation is linked to cellular ATP levels. Circ Res 2004, 95:726-733.

25. Clair C, Chalumeau C, Tordjmann T, Poggioli J, Erneux C, Dupont G, Combettes $\mathrm{L}$ : Investigation of the roles of $\mathrm{Ca}^{2+}$ and $\mathrm{InsP}_{3}$ diffusion in the coordination of $\mathrm{Ca}^{2+}$ signals between connected hepatocytes. J Cell Sci 2001, 114:1999-2007.

26. Pinheiro AR, Paramos-de-Carvalho D, Certal M, Costa C, Magalhães-Cardoso MT, Ferreirinha F, Costa MA, Correia-de-Sá P: Bradykinin-induced $\mathrm{Ca}^{2+}$ signaling in human subcutaneous fibroblasts involves ATP release via hemichannels leading to $\mathrm{P}_{2} \mathrm{Y}_{12}$ receptors activation. Cell Commun Signal 2013, 11:70.

27. Kansui Y, Garland CJ, Dora KA: Enhanced spontaneous $\mathrm{Ca}^{2+}$ events in endothelial cells reflect signalling through myoendothelial gap junctions in pressurized mesenteric arteries. Cell Calcium 2008, 44:135-146.

28. Wang X, Veruki ML, Bukoreshtliev NV, Hartveit E, Gerdes HH: Animal cells connected by nanotubes can be electrically coupled through interposed gap-junction channels. Proc Natl Acad Sci U S A 2010, 107:17194-17199.

29. Kizana E, Chang CY, Cingolani E, Ramirez-Correa GA, Sekar RB, Abraham MR, Ginn SL, Tung L, Alexander IE, Marban E: Gene transfer of connexin43 mutants attenuates coupling in cardiomyocytes, novel basis for modulation of cardiac conduction by gene therapy. Circ Res 2007, 100:1597-1604.

30. Wade MH, Trosko JE, Schindler M: A fluorescence photobleaching assay of gap junction-mediated communication between human cells. Science 1986, 232:525-528.

31. Santiquet NW, Develle Y, Laroche A, Robert C, Richard FJ: Regulation of gap-junctional communication between cumulus cells during in vitro maturation in swine, a gap-FRAP study. Biol Reproduction 2012, 87:1-8.

32. Matsushita S, Kurihara H, Watanabe M, Okada T, Sakai T, Amano A: Alterations of phosphorylation state of connexin 43 during hypoxia and reoxygenation are associated with cardiac function. J Histochem Cytochem 2006, 54:343-353.

33. Evans WH, Leybaert L: Mimetic peptides as blockers of connexin channel-facilitated intercellular communication. Cell Commun Adhes 2007. $14: 265-273$

34. Kwak BR, Jongsma HJ: Selective inhibition of gap junction channe activity by synthetic peptides. J Physiol 1999, 516:679-685

35. Doble BW, Chen Y, Bosc DG, Litchfield DW, Kardami E: Fibroblast growth factor-2 decreases metabolic coupling and stimulates phosphorylation as well as masking of connexin43 epitopes in cardiac myocytes. Circ Res 1996, 79:647-658.

36. Opsahl H, Rivedal E: Quantitative determination of gap junction intercellular communication by scrape loading and image analysis. Cell Adhes Commun 2000, 7:367-375.

37. Dyce PW, Norris RP, Lampe PD, Kidder GM: Phosphorylation of serine residues in the C-terminal cytoplasmic tail of connexin43 regulates proliferation of ovarian granulosa cells. J Membr Biol 2012, 245:291-301. 
38. Li C, Meng Q, Yu X, Jing X, Xu P, Luo D: Regulatory effect of connexin 43 on basal $\mathrm{Ca}^{2+}$ signaling in rat ventricular myocytes. PLoS One 2012, 7:361-365.

39. Harks EG, Camina JP, Peters PH, Ypey DL, Scheenen WJ, van Zoelen EJ, Theuvenet AP: Besides affecting intracellular calcium signaling, 2-APB reversibly blocks gap junctional coupling in confluent monolayers, thereby allowing measurement of single-cell membrane currents in undissociated cells. FASEB J 2003, 17:941-943.

40. Chen J, Pan L, Wei Z, Zhao Y, Zhang M: Domain-swapped dimerization of ZO-1 PDZ2 generates specific and regulatory connexin43-binding sites. EMBO J 2008, 27:2113-2123.

41. Solan JL, Marquez-Rosado L, Sorgen PL, Thornton PJ, Gafken PR, Lampe PD: Phosphorylation of Cx43 at S365 is a gatekeeper event that changes the structure of Cx43 and prevents downregulation by PKC.J Cell Biol 2007, 179:1301-1309.

42. Johnson KE, Mitra S, Katoch P, Kelsey LS, Johnson KR, Mehta PP: Phosphorylation on Ser-279 and Ser-282 of connexin43 regulates endocytosis and gap junction assembly in pancreatic cancer cells. MBOC 2013, 24:715-733.

43. Kucera JP, Rohr S, Rudy Y: Localization of sodium channels in intercalated disks modulates cardiac conduction. Circ Res 2002, 91:1176-1182.

44. Jansen JA, Noorman M, Musa H, Stein M, de Jong S, van der Nagel R, Hund TJ, Mohler PJ, Vos MA, van Veen TA, de Bakker JM, Delmar M, van Rijen HV: Reduced heterogeneous expression of $\mathrm{C} \times 43$ results in decreased Nav1.5 expression and reduced sodium current that accounts for arrhythmia vulnerability in conditional Cx43 knockout mice. Heart Rhythm 2012, 9:600-607.

45. Rhett JM, Ongstad EL, Jourdan J, Gourdie RG: Cx43 associates with $\mathrm{Na}(\mathrm{v})$ 1.5 in the cardiomyocyte perinexus. J Membr Biol 2012, 245:411-422.

doi:10.1186/s12964-014-0058-6

Cite this article as: Kang et al:: Cx43 phosphorylation on S279/282 and intercellular communication are regulated by $\mathrm{IP}_{3} / \mathrm{IP}_{3}$ receptor signaling. Cell Communication and Signaling 2014 12:58.

\section{Submit your next manuscript to BioMed Central and take full advantage of:}

- Convenient online submission

- Thorough peer review

- No space constraints or color figure charges

- Immediate publication on acceptance

- Inclusion in PubMed, CAS, Scopus and Google Scholar

- Research which is freely available for redistribution 